\title{
Access to Water Supply among the Tea Pickers in Sylhet, Bangladesh
}

Shushanta Acharjee ${ }^{\dagger}$ and Shah Imran Ahmed ${ }^{\top}$

\section{Abstract}

The study explores access to water supply system of tea pickers in six tea estates of Sylhet division of Bangladesh-Malnichhera, Lackaturah, Keramotnagor, Balishera, Kalagul and Rashidpur. Drawing upon a systematic set of semi-structured interviews and cross-sectional data collected randomly from 300 tea pickers, the study considers men and women's access to (un)safe water by addressing their sources of both drinking and using water for daily usages and the distances from home to sources by including their concern about safe water and its related diseases.

Key words: Tea Pickers, Tea Gardens, Sustainable Water Management, Water Related Diseases, Sylhet, Bangladesh

\footnotetext{
${ }^{\dagger}$ Former postgraduate student, Sociology, Shahjalal University of Science and Technology, Sylhet-3100, Bangladesh. Email: switsusanta@gmail.com

ī Postgraduate research student, Sociology, Shahjalal University of Science and Technology, Sylhet-3100, Bangladesh. Email: siahmed53@gmail.com

(C) 2016 Acharjee and Ahmed. This is an Open Access article distributed under the terms of the Creative Commons Attribution License (http://creativecommons.org/licenses/by/2.0), which permits unrestricted use, distribution, and reproduction in any medium, provided the original work is properly cited.
} 


\section{Introduction}

Tea is one of the most crucial cash crops in many countries. It is an essential product in terms of jobs and export earnings for many countries including Bangladesh. Bangladesh earns 2,000 million taka (Bangladesh currency) every year by exporting tea, contributing about $0.8 \%$ to the total GDP of Bangladesh (Majumdar and Roy, 2012a). But tea pickers are the most oppressed workers in Bangladesh - they remain deprived from their basic needs and live below the poverty line (Barkat, 2010), leading a life of unimaginable despair (Das and Islam, 2006). Studies revealed the tragic life of tea pickers in terms of working environment, living quality, health security (Khan, 1991; BPMI, 1997; Saha 2001; Ahmed and Chowdhury, 2014) and fail to receive sufficient support from the authority as well as the government (Ahmed et al., 2015). The working environments of tea pickers are often very poor. Lack of protective gears and inadequate basic facilities such as housing, food and sometimes-even drinking water add to their dismay (Majumder and Roy, 2012b). Water is the lifeline to every living being. In some organisms, around nine-tenths of the body weight is made of water. Almost 60 per cent of an adult human body is composed of water (Mitchell et al., 1945). Brain and heart consists of 73 per cent of water and the lungs are nearly 83 per cent watery. The skin comprises 64 per cent of water while muscles along with kidneys consist of 79 per cent of watery. Even the bones are 31 per cent watery. Every day the humans are required to take in a certain amount of water for endurance (Mitchell et al., 1945). Of course; this varies according to age and gender, and by where someone lives. Although water is indispensable for human body but unsafe water causes different kinds of water related diseases. The people using an impure drinking water source are more exposed to water-borne diseases. Throughout the less developed region, the rate of households that use an unclean drinking water source has deteriorated, but it is inconceivable that all households will have a pure drinking water source in the ascertainable future (Chowdhury et al., 2011). UNICEF reports that in 2010, 884 million people in the world used impure drinking water source, and assessment that in 2015, 672 million people are still using unimproved drinking water source (UNICEF, 2010). Worldwide, nearly 950 million people still do not have access to safe water (UNDESA, 2009). Almost 50 per cent population of the developing world does not have access to adequate sanitation facilities and drinking water (WHO/UNICEF, 2010). Over 80 percent of people collect water from unimproved drinking water sources (DFID, 2008). That is why global attention has to focus on supplying safe drinking water. The World Summit on Sustainable Development and the Millennium Development Goal 7 for Environmental Sustainability (UNDP, 2000), 10 targets were about safe drinking water and sanitation. The years between 2005 and 2015 were determined as the decade for "Water for Life" (UNDESA, 2003). The report unravels that across the living planet, a child dies every 15 seconds because of preventable water borne disease and young girls and women spend approximately 200 million hours in fetching drinking water. The results of this report of course match a number of studies conducted in India (Bhattacharyya, 2015; Bhattacharyya and Prasad, forthcoming; Singh, 2014; 2015). In similar context, arguably, sustainable access to water management system in tea gardens of Bangladesh is far more miserable. The major sources of water in Bangladesh are rivers, reservoirs, lakes, canals, ponds, and groundwater in shallow and deep tube-well. In addition, rainwater can also be considered as another important source (Ahmed and Jahan, 2008). Evidently, in Bangladesh the poor continue to suffer from different types of water related diseases using unclean drinking water sources (Ahmed and Rahman, 2000; Majumder and Roy, 2012; Ahmed et al., 2006). Development of sustainable water supply system is crucial to avoiding all kinds of water related disease. According to Brundtland Commission's "Sustainable Development means development that meets the needs of 
the present without compromising the ability of future generations to meet their own needs" (UN WCED, 1987). It also refers to the sufficient availability of water into near future (Schnoor, and Jerald, 2010). The key aim of this study is to examine the sustainable access to water supply system of tea pickers in Bangladesh. In doing so, it aims to understand the status of water supply system of tea pickers of Bangladesh. To accomplish the research, we aim to unfold the water relevant complications faced by the tea workers of Malinichhera, Lackaturah, Kalagul, Rashidpur, Keramotnagor and Balishera tea gardens, all located in the Sylhet division of Bangladesh.

As per the 1962 Labor Ordinance of Bangladesh, it is the responsibility of the garden authorities to ensure supply of adequate quantity of pure drinking water to its labors (Labor ordinance, 1962). However, the findings suggest that maximum tea pickers drink water from very few available tube wells and waterfalls, where most wells remain uncovered. The female workers also complained that due to shortage of tube wells they are required to walk a long distance to collect drinking water, which is a kind of transgression. The following section outlines the key objectives of the study.

\section{Objectives of the study}

- To assess the access to water supply system of the tea pickers.

- To explain the water sources of tea pickers in the tea gardens.

- To discuss what strategy they use to collect and preserve water for daily use.

- To examine the perception regarding safe water among the tea pickers.

\section{Methodology}

Bangladesh has 163 tea gardens (Kamruzzaman et al., 2015). As stated above, for this study, we collected data from six different tea estates of Sylhet division. They are-Malnichhera, Lackaturah, Keramotnagor, Balishera, Kalagul and Rashidpur. Malnichhera, Kalagul and Lackaturah are located in Sylhet district. Keramotnagor and Balishera are situated in Moulovibazar district and the remaining one Rashidpur is situated in Habigonj district.

The research is primarily based on data collected through survey interview schedule containing both open ended and close-ended questions. In addition, secondary data were collected from garden authorities, journals, the internet, and newspapers. The collected data were processed and formulated, avoiding irrelevant and unnecessary information; and were analysed according to the objectives of the study, using different types of statistical tools and techniques.

Out of 3993 tea pickers from six-selected tea gardens, we selected 300 tea-pickers using simple random sampling (Nachmaias and Nachmaias, 1981) and were interviewed considering their age limit, which were between 18-60 years. In order to give more weightage to our research, we also took response from participants who were below 18 and more than 60 years. The location of the respondents in six different tea estates are illustrated in Figure 1-26 per cent from Malnicherra tea estate; 17 per cent and 10 per cent respectively from Balishera and Keramotnagor tea estates; the Lackaturah and Rashidpur tea estates comprised respectively 20 per cent and 15 per cent and the remaining from the Kalagul tea estate. 


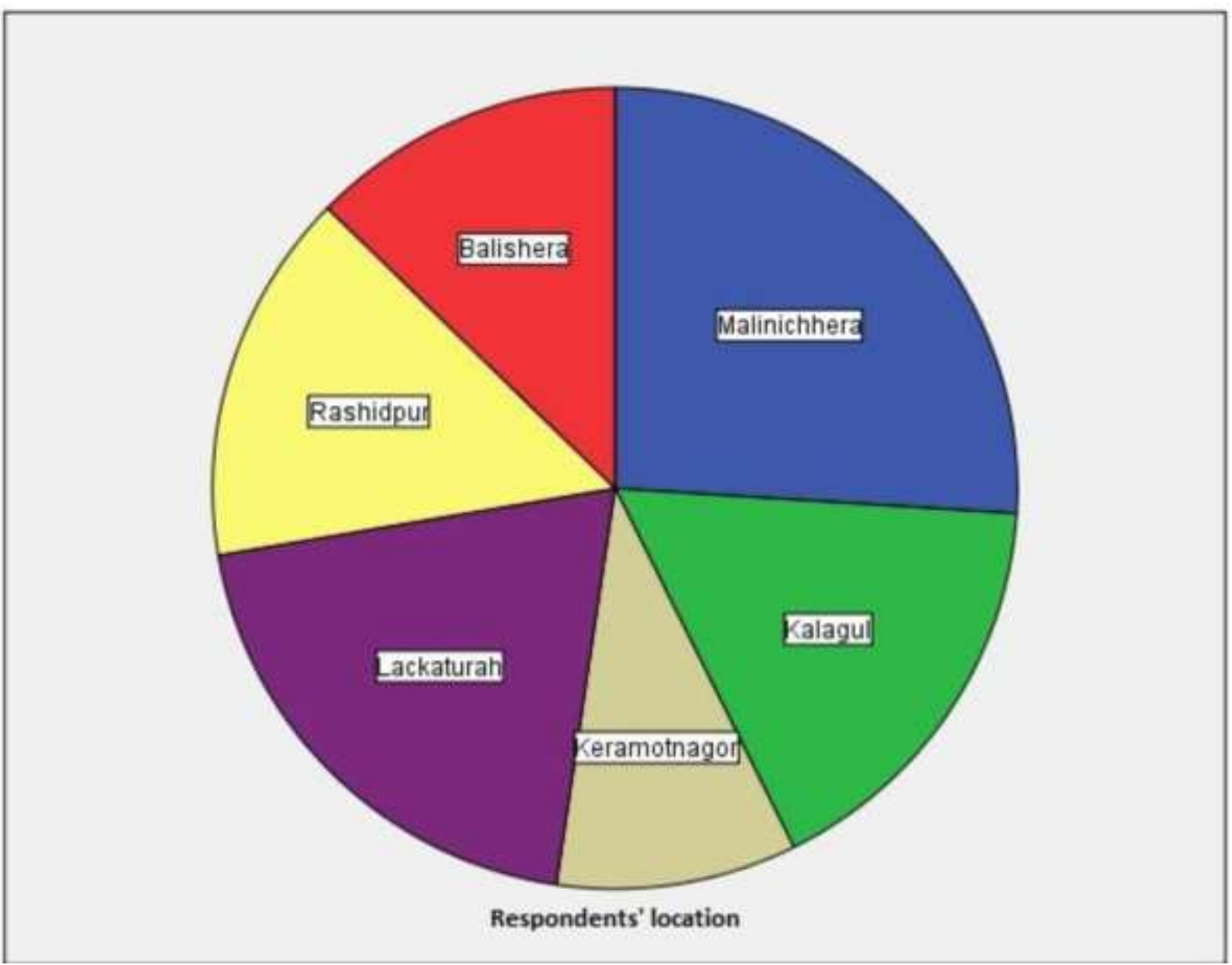

Figure 1: Location of Respondents' in Six Different Tea Estates (Source: Authors)

\section{The Findings}

The results unfold that the tea pickers depend on different kinds of water sources. 54 per cent family use tube wells, 7 per cent household uses water from water supply and 16 per cent use waterfalls, while 23 per cent household collected water from others sources. In order to collect everyday drinking water, the tea pickers need to cover a distance of about 80-180 feet from their homes. However, those households that live nearer to the officers' quarters, they were lucky compared to their counterparts because they cover a small distance of approximately 19 feet to collect water for daily usage. These results bear resonance to the observations made by studies conducted in India (Bhattacharyya, 2015; Bhattacharyya and Prasad, forthcoming; Singh, 2014; 2015). The research findings nevertheless reveal that the tea pickers did not have enough idea about safe water. That said, the study showed that many a times, the people were not aware of whether they were consuming safe water, albeit they were satisfied with whatever they were consuming. Evidently, they collected water from many sources, which are untested. However, 51 per cent people were not satisfied with drinking water service and its quality.

\section{Sources of Drinking Water}

Figure 2 illustrates that the respondents in the six different tea gardens use various water sources for everyday drinking. 72 per cent households use tube wells; while only 6 per cent use piped-water supply; 8 per cent depend on waterfall, and 14 per cent households collected their drinking water from different sources. 


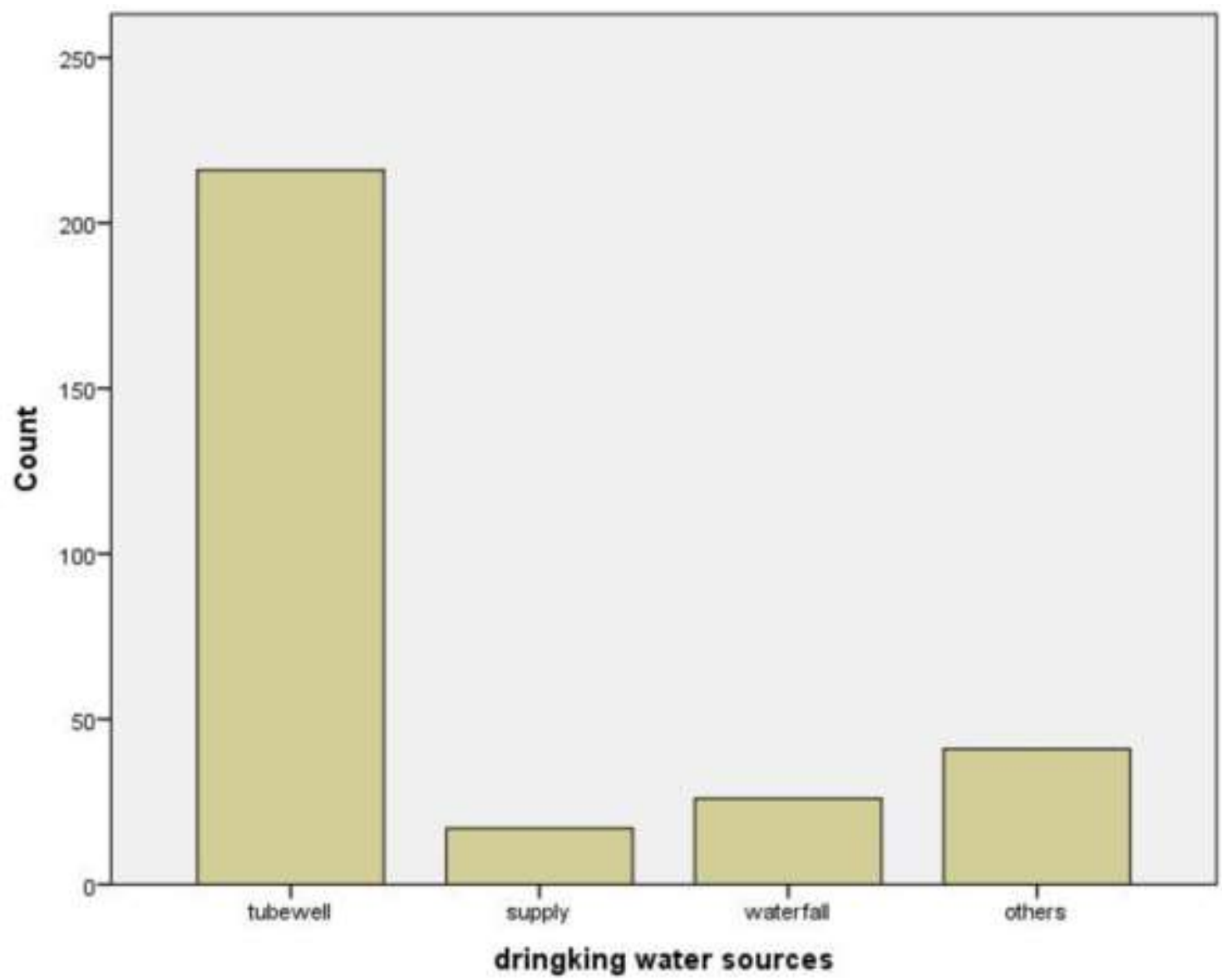

Figure 2: Sources of Drinking Water in the Six Tea Estates (Source: Authors)

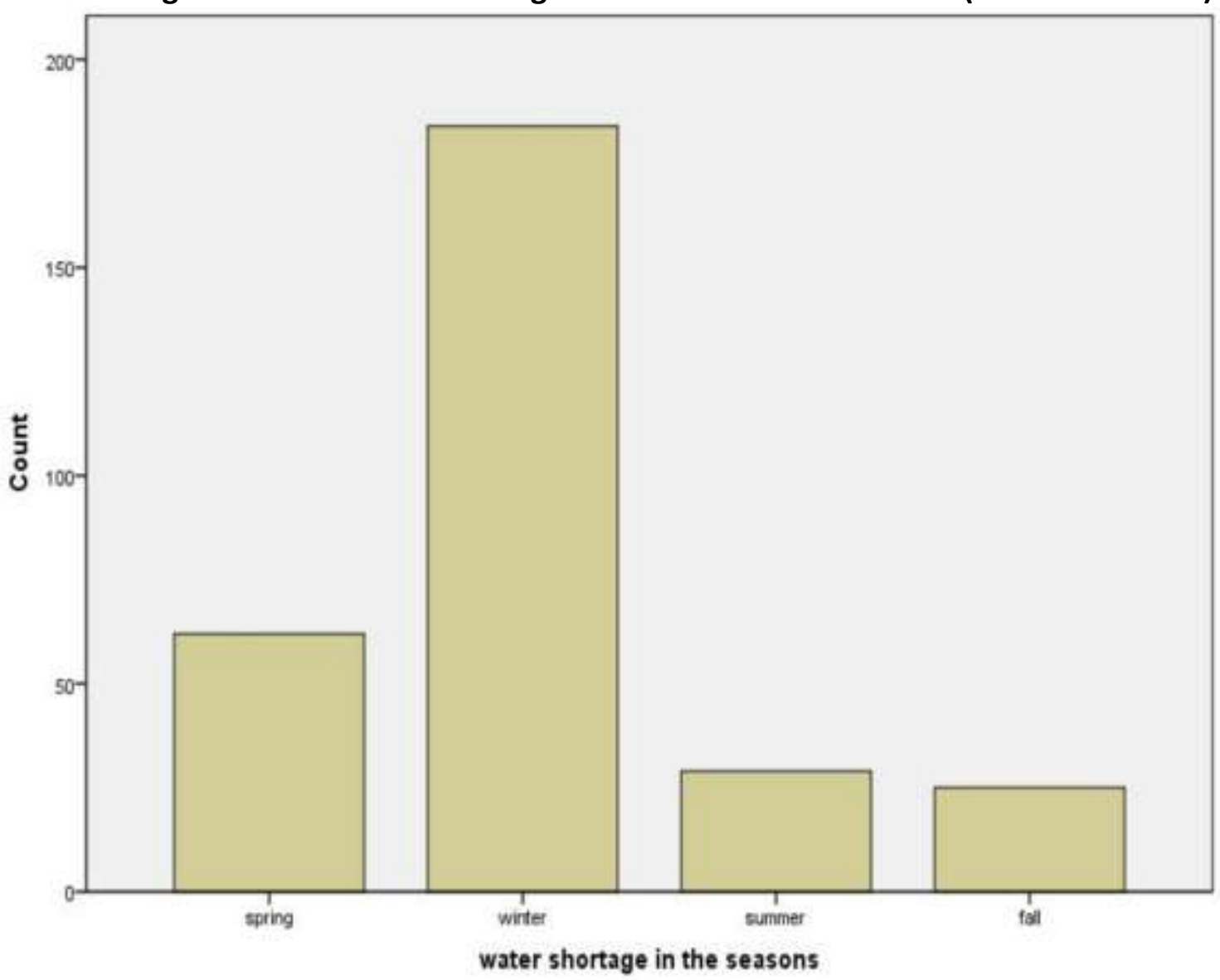

Figure 3: Shortage of Water in Different Seasons in the Six Tea Estates (Source: Authors) 


\section{Water Availability throughout the Year}

Bangladesh as a whole is characterised by subtropical monsoon climate with heavy rainfall, albeit the amount of rainfall varies from season to season. Similarly, availability of water varies from season to season; clearly, implying that in different seasons people suffer from the problems of water shortage but majority of the respondents suffered from water shortage during the winter especially from NovemberFebruary (see, Islam, 2009; Shahid, 2010). This is because, during this time the groundwater table recedes because of low or no rainfall; even the amount of water in the waterfall dwindles. Figure 3 paints the availability of water in different seasons and demonstrates that water shortage is highest in the winter season. Hence, the poor households practice some simple and conventional methods of preserving water. Figure 4 shows the different water collection methods-it demonstrates that more than 56 per cent respondents collect and preserve water in jars; approximately, 28 per cent use different types of pots, while 9 per cent participants used their gallons (large and spacious containers); other 7 per cent respondents used "others" (for example, buckets, etc.) to collect and preserve daily water particularly for night usages. Our next probe was to examine the perceptions of safe water and water management system in the tea gardens.

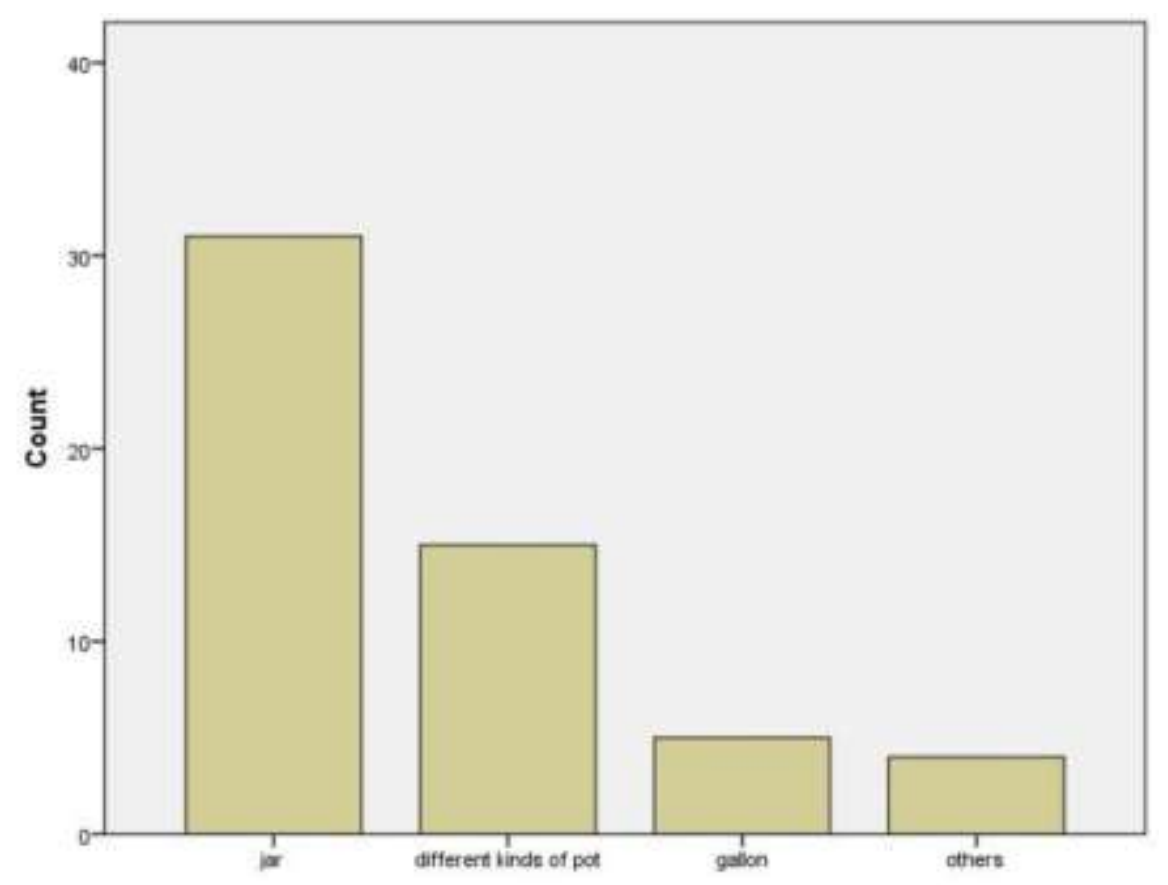

Figure 4: Methods of Water Collection in the Six Tea Estates (Source: Authors)

\section{Perception about Safe Water}

In order to examine the perceptions of safe water we used a scale bearing five possible outcomes. They are-strongly disagree, disagree, neutral, agree and strongly agree. Our first question was-Do you agree that safe water is an important issue for human health? Among the 300 respondents, majority strongly responded that 'safe water' is important to human health and responded that they became aware via watching television, counselling by NGO workers and so on. Similarly, 64 respondents disclosed their opinions as neutral, while 15 and 36 participants responded to the scales of 'strongly disagree' and 'disagree' respectively on the grounds that, they are not concerned about 'safe water'; have little scientific explanation regarding safe water and are not interested to learn or take counselling on safe drinking.

Next, in response to our question-Do you agree that safe water is available throughout the year? Majority of the participants (108 and 101 respectively) responded to being 
disagreeing and strongly disagreeing. Indeed, these participants were indignant of the fact that they greatly suffer from accessing safe drinking water for two-three months in a year. In addition, majority of the participants were required to take arduous steps in travelling long distances daily for collecting and preserving drinking water. Whereas, only 46 and 14 participants respectively responded that they agreed and strongly agreed because they could access safe water throughout the year within a short distance from their homes. These respondents are indeed the participants who reside near the officers' quarters. Likewise, 31 respondents replied that they have no opinions regarding the access to 'safe drinking water' and failed to reply with definite reasons.

\section{Perceptions about Improvement of Water Management System}

Our next question was-Do you agree that the garden authorities are working for the improvement of safe water management system? In response to this question, a majority of the participants responded that they believed that the tea garden authorities are working on to improve the water management system-25 participants strongly felt that positive steps are being taken by the authorities to improve the system by undertaking tasks such as setting up of tube wells and install water supply facilities wherever necessary. However, the degrees of these improved facilities are meagre. On the other hand, 87 and 35participants respectively responded on the scales 'strongly agree' and 'agree' on that the tea management authorities have not done enough to improve the water supply system of the six tea gardens. Instead, as stated above, the participants responded that some NGOs were working to set up tube wells and showing short films and drama on safe water. However, 44 respondents decided not to give their opinion on this matter and opted to remain neutral.

In our next question, we asked-Do you agree that frequency of water supply is sufficient for your need? In response to this answer, majority of the participants either 'disagreed' or 'strongly disagreed'. However, 46 and 20 participants respectively responded that they 'agreed' and 'strongly agreed' on they had sufficient water through the water supply system to carry out their everyday practices. Nevertheless, 39 participants remained neutral. Finally, we asked them-Do you have any experience on suffering from water-related diseases? Accordingly, 88 respondents remained neutral but 58 and 28 respondents respectively opined that they have had no experience regarding water-related diseases. To back up their claims, these 86 respondents marked their opinions using the scale 'strongly disagree' and 'agree' respectively. On the other hand, 84 and 42 respondents expressed their opinions using the scales 'agree' and 'strongly agree' signalling that these participants have suffered from water borne and infectious diseases - such as dysentery and diarrhoea, etc. In addition, some of these diseases were seen among their neighbours.

\section{Conclusion}

The key purpose of this article was to examine the access to water supply system for the tea pickers and to understand the way they preserve water for their daily usage and their perceptions on safe water. The tea pickers are obviously highly deprived sections of the society. We argue that Bangladesh is one of the well-known tea producing nations of the world. From this point of view, tea workers make not only important contributions to the national but also global economy. Therefore, the government, with the help of the owner and management needs to come forward to solve the basic water problems of the tea pickers. The above results has shown that the water supply system is unsustainable, pathetic and miserable because of the distance of water sources, water unavailability throughout the year and lack of the idea about safe water. That there are no proper water management systems for tea pickers in all the tea estates in Bangladesh are evidenced from the research, where the tea pickers collect water from unpurified sources. While this study is an addition to water access literature, it is 
certainly going to serve as a basis for further research on sustainable management of water among the tea pickers. However, following recommendations remains paramount for better management of safe water system among the tea pickers. Evidently, the tea pickers lack knowledge of safe water and as a result, they suffer from infectious and water related diseases, which could be the consequence of direct or indirect result of using unsafe water. However, they fail to realise that it could be the impact of polluted water. Hence, we recommend that the garden authorities must understand the gravity of seriousness of the problem and take efficient steps to provide safe drinking water to all its employees.

More awareness campaigns by NGOs and authorities on water related diseases must be undertaken, perhaps by various showing more short films or dramas on drinking unsafe water and its impact on human body including how it causes different diseases, which might alert the tea pickers to practice usage of safe drinking water.

\section{References}

Ahmad I., Yasin M. Rowshon A, Rafikul Islam A.K.M, (2015). Study on Socio Economic and Educational condition of Tea Worker at Sylhet in Bangladesh, Journal of Tea Science Research, 5(5), 1-8, doi: 10.5376/jtsr.2015.05.0005

Ahmed M., Hoque M.A., Sarkar M.S.K.A., Chowdhury M.A.I., and Begum A. (2006). SocioCultural Evaluation of Sanitation Hygiene in Sylhet City of Bangladesh, ARPN Journal of Engineering and Applied Sciences, 1(3), ISSN 1819-6608

Ahmed, M.F. and Jahan, H. (editors). (2008). Participatory Management of Water Supply and Sanitation, ITN-Bangladesh Centre for Water Supply and Waste Management, BUET, October 2000.

Ahmed, M.F, and Rahman, M.M., (2000). Water Supply and Sanitation: Rural and Low -Income Urban Communities, ITN-Bangladesh Centre for Water Supply and Waste Management, BUET, June 2000, ISBN 984-31-0936-8
Ahmed S. and Chowdhury S.R. (2014). The Rights of Tea Workers of Bangladesh in the Light of Existing Labor Laws and Standards: A Study on Selected Tea Estates of Sylhet District, International Journal of Research in Commerce, IT \& Management, 4 (7). Haryana, India, ISSN 2231-5756

Barkat, A. (2010). Assessment of the Situation of Children and Women in the Tea Gardens of Bangladesh, Planning, Monitoring and Evaluation Department of UNICEF-BCO, Human Development Research Center, Dhaka, Bangladesh. Dhaka: September 2010.

Bhattacharyya, R. (2015). Book ReviewDyson, Jane 2014: Working Childhoods: Youth, Agency and the Environment in India. Cambridge, United Kingdom: Cambridge University Press, 186 pages, £50.00, Hardback ISBN: 9781107058385, Progress in Development Studies, 15(3), 292-294, DOI: $10.1177 / 1464993415578570$

Bhattacharyya, R. and Prasad Sanjay (2016, forthcoming). Chapter 6. Water Scarcity in Delhi: Mapping for Solutions and the Way Forward. In Dr. R.B. Singh, Dr. Daniel Karthe Helmholtz and Dr. Sergey Chalov (eds.) Water and Sediments in Changing Environment of Eurasia-Advances in Geographical and Environmental Sciences, Springer Publications: International Geographical Union (IGU-UGI).

BPMI report (1997). Bangladesh Project Management Institute Baseline Survey of the Tea Plantation Workers and their Families in Bangladesh, ILO.

Chowdhury M.A.I., Hasan G.M.J., and Karim M.A. (2011). A Study on Existing WATSAN Condition of Two Tea Gardens in Maulvibazar, Environmental Science \& Natural Resources, $4(2), 13-18$.

Das T.K., and Islam S.M., Zakirul H. (2006). Human Rights of the Tea Gardeners: Case Study of Selected Gardens in Sylhet, Asian Affairs, 28(3), 1-4.

DFID (2008). Water and Sanitation Policy Water: An Increasingly Precious Resource Sanitation: A Matter of Dignity. Retrieved 
from:http://www.dfid.gov.uk/Documents/publi cations/water-sanitation-policy-08.pdf

(Accessed February 2010).

Islam, Md. Nazrul (2009). Rainfall and Temperature Scenario for Bangladesh, The Open Atmospheric Science Journal, 3, 93-103. Retrieved from: http://benthamopen.com/contents/pdf/TOASC J/TOASCJ-3-93.pdf

Kamruzzaman, Md, Parveen, Shahnaj and Das Chandra, Animesh (2015). Livelihood Improvement of Tea Garden Workers: A Scenario of Marginalized Women Group in Bangladesh, Asian Journal of Agricultural Extension, Economics \& Sociology, AJAEES.18690, 1-6.

Khan M.R. (1991). Primary Health Care Status of the Tea Estate Population, A Study Conducted for the Bangladesh Tea Rehabilitation on Project, Bangladesh Institute of Development Studies, BIDS, Bangladesh.

Majumder S.C., and Roy S.C. (2012). SocioEconomic Conditions of Tea Plantation Workers in Bangladesh: A Case Study on Sreemongal, Indian Journal of Applied Research, Gujarat, India, I(X), 1-6.

Mitchell H.H, Hamilton, T.S, Steggerda, F.P. and Bean, H.W. (1945).The Chemical Composition of the Adult Human Body and Its Bearing on the Chemistry of Growth. Journal of Biological Chemistry, 158, 625-637.

Nachmaias,C. and Nachmais, D. (1981). Method in Social Science, London: Edward Arnold LTD ISBN-13: 978-1429233002

Saha J.K. (2001). A Study to Assess the SocioEconomic Status in the Context of Working Efficiency of Tea Workers in Bangladesh, Bangladesh Tea Research Institute, Bangladesh Agricultural Research Council, 2-8.

Schnoor, L. and Jerald, L. (2010). Water Sustainability in a Changing World, Annual Clarke Prize Award Ceremony and Lecture, Orange County Performing Arts Center in Cosa Mesa, California, 2-4.

Shahid, Shamsuddin (2010). Rainfall Variability and the Trends of Wet and Dry Periods in
Bangladesh, International Journal of Climatology, 30, 2299-2313, DOI:

10.1002/joc.2053

Singh, S. B. (2015). Women as Milieu Managers in Integrated Watershed Management: Perspectives from the Hilly Areas of Uttarakhand, Journal Space and Culture, India, 2(4), 71-79, DOI:

http://dx.doi.org/10.20896/saci.v2i4.130

Singh, Suman (2014). Women, Environment and Sustainable Development: A Case Study of Khul Gad Micro Watershed of Kumoun Himalaya, Space and Culture, India, 1(3), 53-64, DOI: http://dx.doi.org//10.20896/saci.v1i3.45

Tea plantations labor ordinance 1962, (No.39 of 1962).

UNDESA (December, 2003). Water for Life

Decade, Retrieved from:

http://www.un.org/waterforlifedecade (December 23, 2003).

UNDESA, (2009). Millennium Development Goals Report 2009. New York, United Nations Department of Economic and Social Affairs.

United Nations Children's Fund (UNICEF), (2010). Progress on Sanitation and Drinking Water. New York: UNICEF.

United Nations World Commission on Environment and Development (UN WCED). Our Common Future: Report of the World Commission on Environment and Development; Document A/42/427, United Nations: New York, NY, USA, 1987.

UNDP, (2000). Report on Millennium Development Goals, United Nations Development Programme. Retrieved from: http://www.un.org/millennium/summit.htm (Accessed January 12, 2015).

WHO/UNICEF (2010). Report of the WHO/UNICEF Joint Monitoring Programme on water Supply and Sanitation. New York and Geneva, United Nations Children's Fund and the World Health Organization. 